\title{
Should Gastric Sleeve be fixed? Torsion of Gastric Sleeve after Laparoscopic Sleeve Gastrectomy: A Case Report
}

\author{
Gupta Paritosh, Khan Shavez, Thusoo Tk and Kaushal Anshuman* \\ Department of Surgery, MIS \& Bariatric Surgery, Artemis Hospitals, India
}

Submission: February 18, 2017; Published: February 23, 2017

*Corresponding author: Anshuman Kaushal, Academic Cordinator and Sr Consultant Surgeon, Department of General, MIS \& Bariatric Surgery, Artemis Hospitals, Gurgaon, 122001, India, Tel: +91- 9910-481-350; Email: kaushal.anshuman@gmail.com

\section{Introduction}

The stomach is normally positioned and fixed by gastrohepatic, gastrosplenic and gastrocolic ligaments. Gastric volvulus (GV) occurs primarily when the stomach suffers torsion on itself due to the laxity or elongation of these attachments or due to fixation at a specific point such as adhesions, diaphragmatic and hiatal hernias or tumors. GV may be mesenteroaxial (torsion of stomach along its short axis), organoaxial (gastric torsion along its long axis), and mixed (Mesenteroaxial and Organoaxial) [1]. Laparoscopic sleeve gastrectomy ia found to be an effective standalone procedure for the treatment of morbid obesity [2]. Although LSG functions as a restrictive procedure, it may also cause early satiety by removing the ghrelin-producing portion of the stomach [3]. The most common complications related to SG are leaks (0.7\%), abscesses (0.7\%), hemorrhages $(0.7 \%)$, and strictures $(0.7 \%)$ [3]. Furthermore, its mortality rate $(0.5 \%)$ is quite low [4]. SG popularity globally has grown significantly among bariatric procedures and now encompasses $27.8 \%$ of surgeries performed in the past 8 years [5]. Due to this rapid growth in numbers of LSG, new complications are sure to arise. Once SG has been performed, Sleeve gastrectomy leaves the stomach with no fixations along the entire greater curvature, which may predispose to volvulus $[6,7]$.

Case Report

a

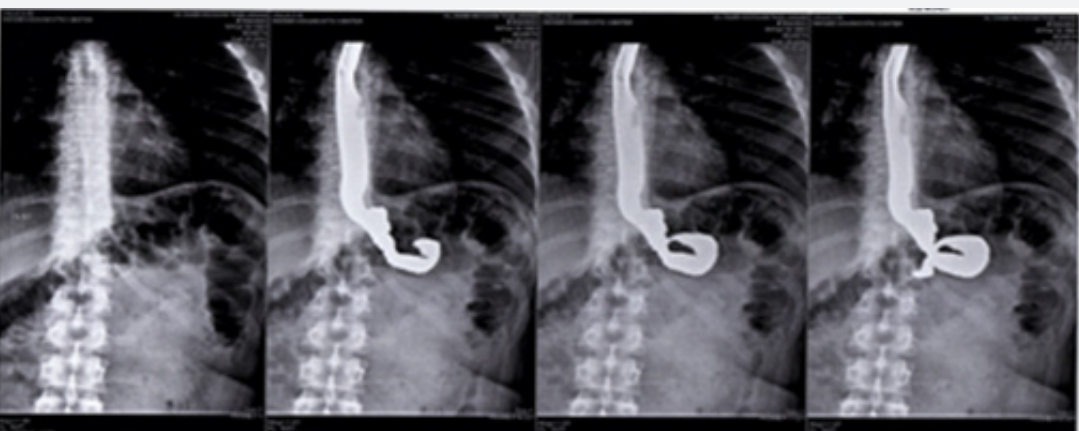

$1 \mathrm{~b}$

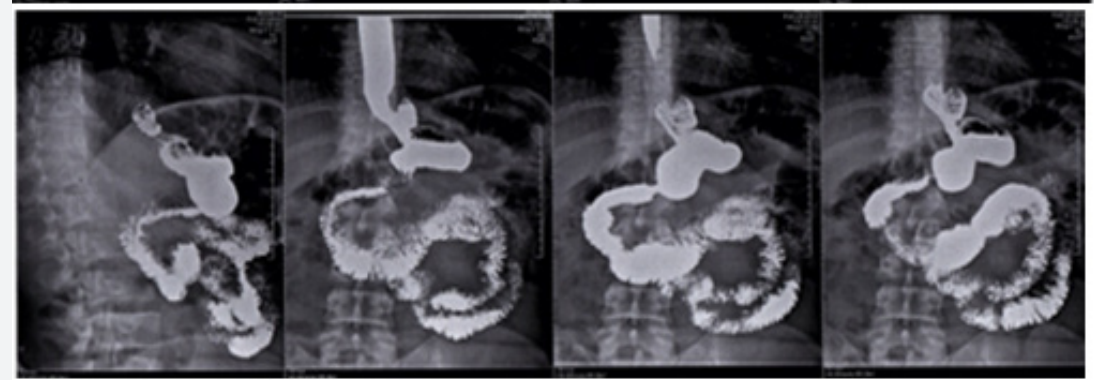

Figure 1a \& 1b: Gastrograffin Swallow showing torsion of the proximal part of the stomach resulting in loop formation and mild dilation of the distal esophagus and mild gastroesophageal reflux with delay of the contrast passage to duodenum due to loop formation, no significant stenosis seen. 
A 33-year-oldman, with initial BMI of $54.08 \mathrm{~kg} / \mathrm{m} 2$ and comorbidities including hypertension, dyslipidemia and gastroesophageal reflux diseaseunderwent SG. His recovery was uneventful. He subsequently presented with dysphagia, dyspepsia and recurrent vomiting one month after the SG. Barium meal finding suggestive of torsion of the proximal part of the stomach resulting in loop formation and mild dilation of the distal esophagus and mild gastroesophageal reflux with delay of the contrast passage to duodenum due to loop formation,no significant stenosis seen. Endoscopy findings demonstrated that the SG had no stricture, but an anticlockwise twist of the distal sleeve was noted which was nonobstructive. Diagnostic laparoscopy revealed organoaxial GT secondary to adhesions between the staple line of sleeve and the liver, falciform ligament and pancreatic fascia (Figures 1 \& 2). Alaparoscopic lysis of adhesion was performed; the stomach was untwisted and returned to the normal anatomic position.Intraoperative upper GI endoscopy was done to confirm detorsion and theanterior wall of sleeve fixed to the greater omentum, gastrocolic ligament and fascia over the pancreas in lesser sac to maintaining correct sleeve orientationwith non absorbable polypropelene 2-0 suture to prevent recurrent torsion. Patient had an uneventful recovery and he started tolerating liquids almost immediately.

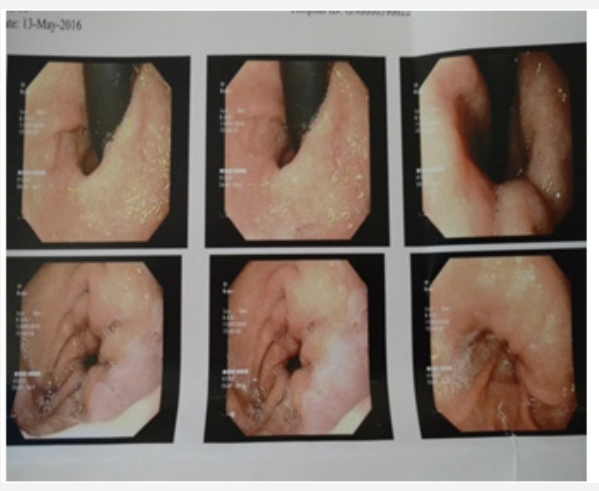

$2 a$

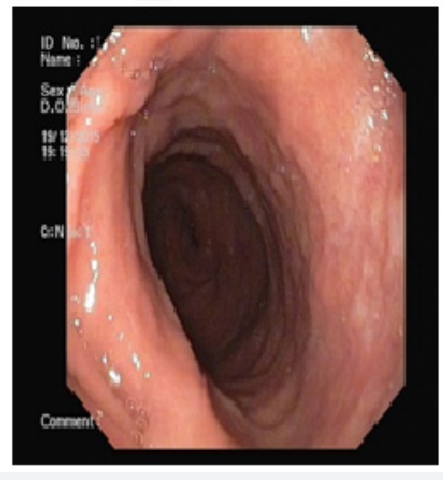

$2 b$

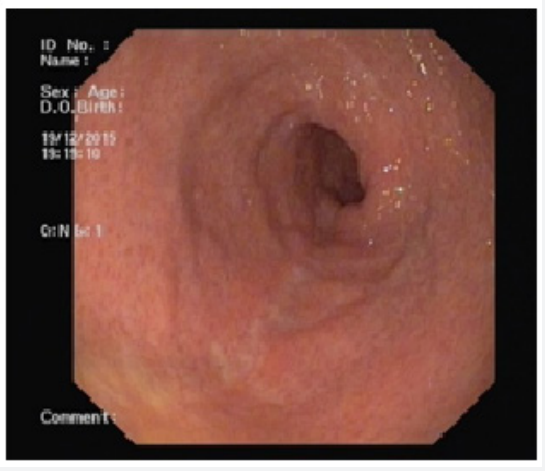

Figure 2a: UGI endoscopy shows fundal dilatation \&twisting rather than obstruction of stomach body.

b: After correction of volvulusby anchorhing of the antral region.

\section{Discussion}

GT can be present as an acute abdominal emergency or a chronic cause of abdominal pain,disgnosed by Borchardt triad, which consists of epigastric pain, unproductive retching and inability to pass a nasogastric tube [8]. GT may be chronic if the rotation is minimal and there is no vascular compromise. Symptoms usually consist of intermittent upper abdominal pain, early satiety, abdominal fullness along with belching. Ischemia might be a complication, which can lead to gastric necrosis and, if untreated, shock and death [9]. The stomach is strongly fixed proximally at the cardiac and distally by the retroperitoneal first part of duodenum. Supporting these 2 points, the gastrophrenic, gastrosplenic, gastrocolic, and gastrohepatic ligaments hold the stomach in place in order to prevent GT [10]. Even the agenesis of gastrocolic ligament only has been related with acute primarily GT with partial gastric necrosis [11].

\section{Conclusion}

During the SG creation, the gastrophrenic, gastrocolic, gastrosplenic, and the posterior gastric attachments are divided $[12,13]$ so the probability of twisting, turning, or folding is quite high. In some cases during SG, the neo gastric tube may coil that may cause obstructive symptoms. In order to prevent this coiling/twisting, some surgeons have recommended that fixation to the greater omentum to the stomach will keep it in the correct position [14]. In our patients, the endoscopy was a very valuable tool for the establishment of GT. Diagnostic Laparoscopy revealed organoaxial torsion, due to the development of adhesions between the staple line of gastric sleeve and the surrounding structures. This was due to lack of the normal gastric attachments. Therefore, we rec-ommend routine fixation of gastric sleeve withn omentum as well as with pancreatic fascia posteriorly $[2,15]$.

\section{References}

1. Jeyarajah DR, Harford WV (2010) Abdominal hernias and gastric volvulus. In: Feldman M, Friedman LS, Brandt LJ (Eds.) Sleisenger and Fordtran's Gastrointestinal and Liver Disease. Vol 1, ( $9^{\text {th }}$ edn), Saunders, New York, USA, 383-385.

2. Hutter MM, Schirmer BD, Jones DB, Ko CY, Cohen ME, et al. (2011) First report from the American College of Surgeons Bariatric Surgery Center Network: laparoscopic sleeve gastrectomy has morbidity and effectiveness positioned between the band and the bypass. Ann Surg 245(3):410-422.

3. Lalor PF, Tucker ON, Szomstein S, Rosenthal RJ (2008) Complications after laparoscopic sleeve gastrectomy. Surg Obes Relat Dis 4(1): 33-38.

4. Frezza EE, Reddy S, Gee LL, Watchel MS (2009) Complications after sleeve gastrectomy for morbid obesity. Obes Surg 19(6): 684-687.

5. Buchwald H, Oien DM (2013) Metabolic/bariatric surgery worldwide 2011. Obes Surg 23(4):427- 436. 
6. Del Castillo Déjardin D, Sabench Pereferrer F, Hernàndez Gonzàlez M, Blanco Blasco S, Cabrera Vilanova A (2013) Gastric volvulus after sleeve gastrectomy for morbid obesity. Surgery 153(3): 431-433.

7. Nassif PA, Valadão JA, Malafaia O, Torres OJ, Garcia RF, et al. (2013) Technical modification for sleeve gastrectomy. Arq Bras Cir Dig 26(1): 74-78.

8. Ajao OG (1980) Gastric volvulus: a case report and review of the literature. J Natl Med Assoc 72(5): 520-522.

9. Hess J, Lowell M (2014) Esophagus, stomach, and duodenum. In: Marx J, Hockberger R, Walls R, eds. Rosen's Emergency Medicine: Concepts and Clinical Practice. Vol 1, ( $8^{\text {th }}$ edn.) Saunders, New York, USA, 11801181.

10. Smith RJ (1983) Volvulus of the stomach. J Natl Med Assoc 75(4): 393397.

11. Mazzei C, Palatucci V, Pollio A, della Corte M, Lombardi D (2013) Partial gastric necrosis due to acute gastric volvulus secondary to agenesis of the gastrocolic ligament. Int J Colorectal Dis 28(9): 1315-1316.

12. Akkary E, Duffy A, Bell R (2008) Deciphering the sleeve: technique, indications, efficacy, and safety of the sleeve gastrectomy. Obes Surg 18(10): 1323-1329.

13. Romero RJ, Kosanovic R, Rabaza JR, Seetharamaiah R, Donkor C, et al. (2013) Robotic sleeve gastrectomy: experience of 134 cases and comparison with a systematic review of the laparoscopic approach. Obes Surg 23(11): 1743-1752.

14. Santoro S (2007) Technical aspects in sleeve gastrectomy. Obes Surg 17(11): 1534-1535.

15. Bellorin O, Lieb J, Szomstein S, Rosenthal RJ (2010) Laparoscopic conversion of sleeve gastrectomy to Roux-en-Y gastric bypass for acute gastric outlet obstruction after laparoscopic sleeve gastrectomy for morbid obesity. Surg Obes Relat Dis 6(5): 566-568.

\section{Your next submission with Juniper Publishers} will reach you the below assets

- Quality Editorial service

- Swift Peer Review

- Reprints availability

- E-prints Service

- Manuscript Podcast for convenient understanding

- Global attainment for your research

- Manuscript accessibility in different formats

( Pdf, E-pub, Full Text, Audio)

- Unceasing customer service

Track the below URL for one-step submission https://juniperpublishers.com/online-submission.php 